\title{
Method and Criteria to Evaluate Reheat Cracking Susceptibility
}

\author{
The notched C-ring test method and evaluation criteria is used to \\ evaluate reheat cracking susceptibility in the coarse grain heat-affected zone \\ of 2.25CriMo0.25V steel
}

BY L. ZHANG, K. WANG, Y. HUANG, C. XU, AND J. CHEN

\begin{abstract}
Due to a lack of facile methods for evaluating the reheat cracking susceptibility of the coarse grain heat-affected zone (CGHAZ), a simple notched $\mathrm{C}$-ring reheat cracking test method and evaluation criteria were proposed. Accordingly, a suitable C-ring sampling method and heat treatment procedure were established. The C-ring specimens were taken from thick plate joints welded under five different heat inputs and testing was carried out. Reheat cracks were observed and identified under different stress loadings. Subsequently, related with the evaluation criteria of the Gleeble ${ }^{\circledR}$ test, the evaluation criteria based on notched C-ring tests were developed. This method can reflect both the microstructure and restraint stress of actual welded joints, and the stress relaxation during heat treatment. Moreover, the experimental operation is simple and repeatable. It is expected that an evaluation standard for reheat cracking sensitivity in CGHAZ will be established.
\end{abstract}

\section{KEYWORDS}

- Reheat Cracking • Notched C-Ring Test

- Evaluation Criteria - Coarse Grain Heat-Affected Zone

- 2.25CriMo0.25V Steel

The hydrogenation reactor, which is used in the petrochemical industry, is primarily fabricated from $2.25 \mathrm{Cr}$ $1 \mathrm{Mo} 0.25 \mathrm{~V}$ steel. Due to the addition of strong carbide-forming elements (e.g., vanadium and titanium), the properties of the steel, such as mechanical behavior under high temperature, creep rupture strength, and resistance to hydrogeninduced cracking, are significantly improved. However, reheat cracking sensitivity of the welded joint is increased (Refs. 1, 2). During postweld heat treatment (PWHT) or service, reheat cracking typically occurs in the weld metal and coarse grain heat-affected zone (CGHAZ), and the reheat cracking sensitivity of the CGHAZ is generally higher than that of the weld metal. Reheat cracking is generally manifested by an intergranular cracking along prior austenite grain boundaries. Finding the crack through conventional, nondestructive examination is difficult. Therefore, reheat cracking is extremely concealed and has dangerous potential (Ref. 3). Around 2008 (Ref. 4), reheat cracking frequently took place in nearly $30 \mathrm{Cr}-\mathrm{Mo}-\mathrm{V}$ steel hydrogenation reactors in Europe. Additionally, in Shaanxi, China, the Shaanxi Yanchang Coal Yulin Energy and Chemical Co. Ltd. found reheat cracking problems in several hydrogenation reactor welded joints (Ref. 5). Between 2009 and 2010 (Ref. 6), a lot of equipment was found to have reheat cracks during inspection. For example, two hydrogenation reactors at Guangzhou Petrochemical and Hainan Refinery in China were discovered to have reheat cracks during a first inspection. In China, from 2011 to 2016, newly built high-temperature boiler reheaters with $600 \mathrm{MW}$ or more had leakage accidents due to reheat cracks in the welded joints of dissimilar steel pipes (Refs. 7, 8).

Mechanical evaluation methods for reheat cracking sensitivity include the high-temperature slow strain rate tensile test, Gleeble ${ }^{\circledR}$ simulation test, C-ring test, Y-groove crack test, and implant test. In 2009, ArcelorMittal, a steel and mining company (Ref. 3), proposed a chemical composition factor called $\mathrm{K}_{\text {factor }}$, to evaluate the sensitivity of reheat cracking in the weld metal of $2.25 \mathrm{Cr} 1 \mathrm{Mo} 0.25 \mathrm{~V}$ steel by the content of trace elements. The expression is: $\mathrm{K}_{\text {factor }}=\mathrm{Pb}+\mathrm{Bi}$ $+0.03 \mathrm{Sb}<1.5 \mathrm{ppm}$. The determination of trace elements in this method requires the use of high-precision chemical analysis methods, such as glow discharge mass spectrometry, which are highly demanding on equipment and generally difficult to perform. This method has major limitations in use. Pillot et al. (Ref. 9) proposed the high-temperature tension test, based on the relationship between the $\mathrm{K}_{\text {factor }}$ and the reduction of area (RoA), to evaluate the reheat cracking sensitivity of $2.25 \mathrm{Cr} 1 \mathrm{Mo} 0.25 \mathrm{~V}$ steel weld metal. This method was included in API 934A (Ref. 10). The welding process was specified in the standard and a sampling is performed in the weld area. The sample must be performed at a strain rate of $5 \times 10^{-4}$ at $650^{\circ} \mathrm{C}$. The average value of the two samples of RoA was greater than $32 \%$, and the RoA of the single sample was greater than $29 \%$. The Gleeble ${ }^{\circledR}$ simulation test was proposed by Vinckier et al. (Ref. 11), based on the relationship between the RoA and the reheat cracking sensitivity of high-temperature tensile specimens, and can be used to evaluate the reheat cracking sensitivity of the 


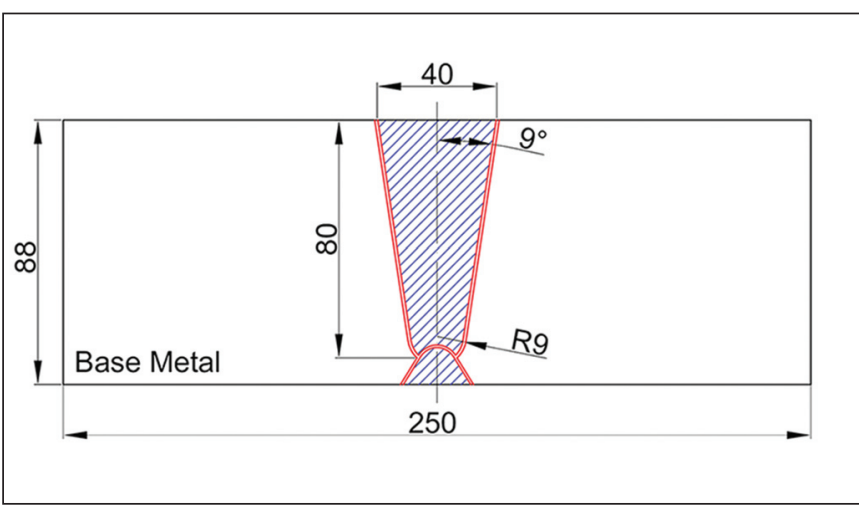

Fig. 1-Geometry of the plate and weld joint.

weld metal and CGHAZ. The Gleeble ${ }^{\circledR}$ simulation test applies to most test procedures and is widely recognized (Ref. 9). However, this method requires strict test conditions. Further, thermal simulation parameter determination and the thermal simulation microstructure screening process are complicated.

Lundin et al. proposed the use of the $\mathrm{C}$-ring test to evaluate the sensitivity of reheat cracking in the heat-affected zone of Cr-Mo steel welds (Refs. 12, 13). In 2012, Maxwell et al. (Ref. 14) improved the notched $C$-ring test and proposed a notched C-ring test of weld deposits to evaluate the sensitivity of reheat cracking in the weld zone of $2.25 \mathrm{Cr}-1 \mathrm{Mo} 0.25 \mathrm{~V}$ steel. With the test, the sensitivity of reheat cracking was evaluated by the magnitude of stress and whether the root of the notch was cracked after heat treatment. The evaluation criteria for reheat cracking sensitivity of the welds obtained were as follows: > $590 \mathrm{MPa}$ - not susceptible;

$<590 \mathrm{MPa}$ - slightly susceptible; $<480 \mathrm{MPa}$ - highly susceptible; and $<380 \mathrm{MPa}$ - extremely susceptible. Test specimens obtained directly from the weld can accurately reflect the actual situation of the weld. The test operation is simple and convenient. However, it is only suitable for evaluating the reheat cracking sensitivity of weld metal.

In summary, to evaluate the reheat cracking sensitivity of 2.25Cr1Mo0.25V steel CGHAZ, with the exception of the Gleeble ${ }^{\circledR}$ simulation test, there are still no other common test methods or specific evaluation criteria. To evaluate the reheat cracking sensitivity of $2.25 \mathrm{Cr} 1 \mathrm{Mo} 0.25 \mathrm{~V}$ steel CGHAZ simply, effectively, and accurately, this study further developed and perfected the CGHAZ notched C-ring test based on the previous studies of Lundin et al. New evaluation criteria for reheat cracking sensitivity and general test guidance procedures were proposed. The CGHAZ notched C-ring test has many advantages, such as low equipment requirements, a simple test process, and high reproducibility, which is of great significance for the popularization of the method, prevention of reheat cracking, and research on the mechanism of reheat cracking.

\section{Material and Methods}

\section{Material}

The base metal used was made of $2.25 \mathrm{Cr} 1 \mathrm{Mo} 0.25 \mathrm{~V}$ steel from the Wuyang Steel Co. in China. The supply state of the base material was normalizing and tempering. The main chemical composition is listed in Table 1, satisfying the requirements of National Standard GB713-2014 (Ref. 15). The surface of the base material was cleaned by shot peening to remove the oxides. The welding consumable materials were made by the Japanese company KOBELCO. The welding wire type was US-521H, and the welding flux type was PF-500. The welding wire chemical composition is listed in Table 2. Before welding, welding consumable materials were preheated at $350^{\circ} \mathrm{C}$ for $2 \mathrm{~h}$.

\section{Welding Procedures and Welding Heat Treatment}

The welded joint was a multilayer, multipass weld made by an automatic submerged arc welding machine. The size of the U-groove is shown in Fig. 1 . The groove is $9 \mathrm{deg}$.

Notched C-ring test welding parameters are summarized in Table 3 . The welding step was followed by dehydrogenation heat treatment, also referred to as postheating at $350^{\circ} \mathrm{C}$ $\left( \pm 10^{\circ} \mathrm{C}\right)$ for $4 \mathrm{~h}$. However, the welded joint was not exposed to a high-temperature heat treatment, such as an intermediate stress relieving heat treatment or postweld heat treatment, because these heat treatments may lead to reheat cracking on the CGHAZ immediately.

\section{C-Ring Sampling and Post Treatment}

Two C-ring sampling methods - Method A (Fig. 2A) and Method B (Fig. 2B) (Ref. 16) - were used to evaluate the influence on the test results. The sampling position of the $C$-ring

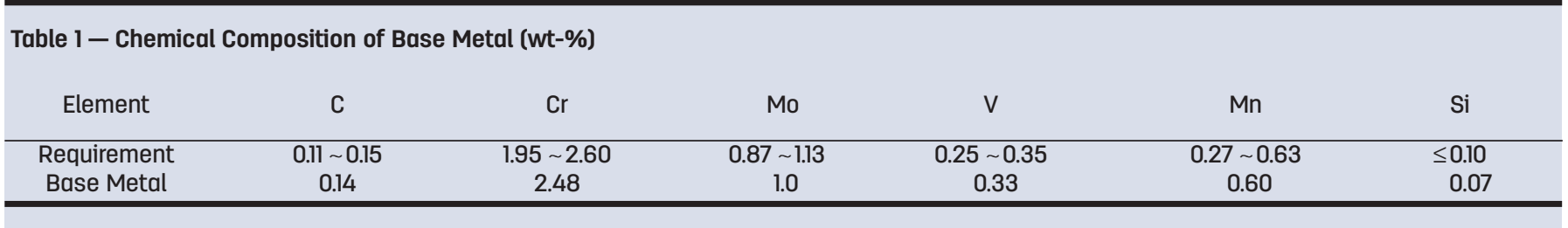

Table 2 - Chemical Composition of Welding Wire (wt-\%)

\begin{tabular}{ccccccccccccc} 
Element & $\mathrm{C}$ & $\mathrm{Si}$ & $\mathrm{Mn}$ & $\mathrm{P}$ & $\mathrm{S}$ & $\mathrm{Cu}$ & $\mathrm{Ni}$ & $\mathrm{Cr}$ & $\mathrm{Mo}$ & $\mathrm{V}$ & $\mathrm{Nb}$ \\
\hline Welding Wire & 0.13 & 0.17 & 1.17 & 0.003 & 0.001 & 0.13 & 0.02 & 2.53 & 1.05 & 0.39 & 0.02 \\
\hline
\end{tabular}




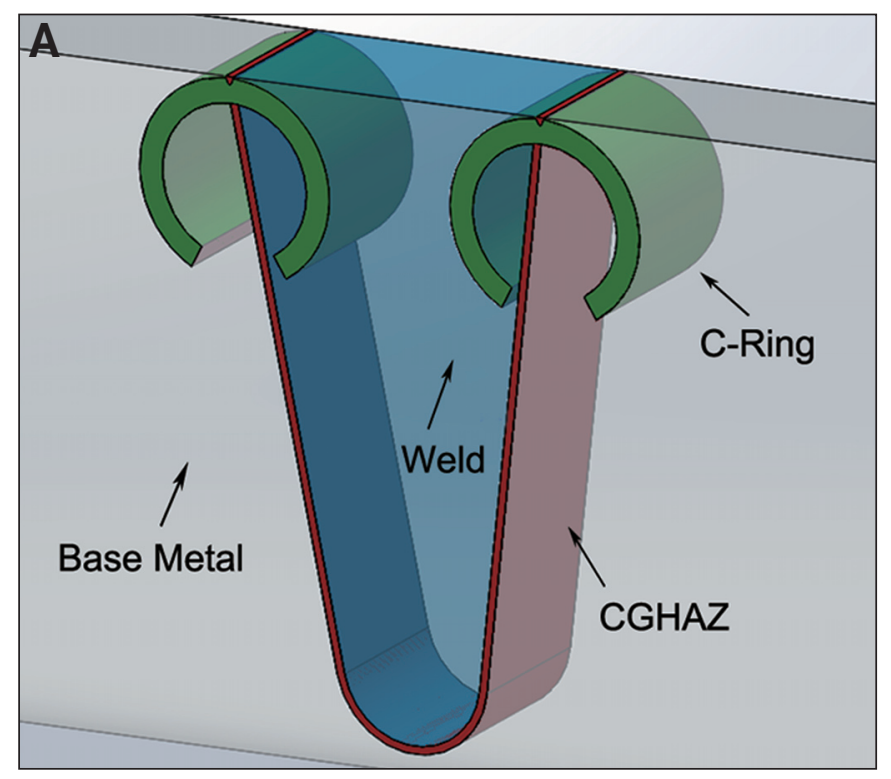

Fig. 2 - Position of $C$-rings inside the welded zone: $A-$ Method A; B - Method B.

was as close as possible to the test plate top, ensuring that the $\mathrm{C}$-ring notched root was located at the uppermost weld to the welded joint. The front and end parts of the plate were affected by the welding process, causing microstructure, which was not representative of the plate as a whole. Therefore, to avoid any influence on the test results, at least $50 \mathrm{~mm}$ from the front and end parts of the plate were cut off.

Notched C-ring test specimens were machined by a wirecutting machine. The specimens were etched in advance before machining to ensure the notch was in the CGHAZ. The notched C-ring specimen geometry is given in Fig. $3 \mathrm{~A}$, and the dimensions are mandatory. The bolts and nuts (Fig. 3A) were made from the same material as the test $C$-ring. After the machining process, the specimen (Fig. 3B) was carefully cleaned in alcohol, acetone, or another suitable solvent. According to ASTM G-38, Standard Practice for Making and Using C-Ring Stressing-Corrosion Test Specimen (Ref. 17), the relationship between the outer diameter deflection and stress at the notched root is shown as

$$
\Delta=\frac{\left(f \pi D^{2}\right)}{4 E t Z}
$$

where $\Delta$ is the outside diameter deflection, mm. The measuring position is parallel to the bolt loading direction, passing

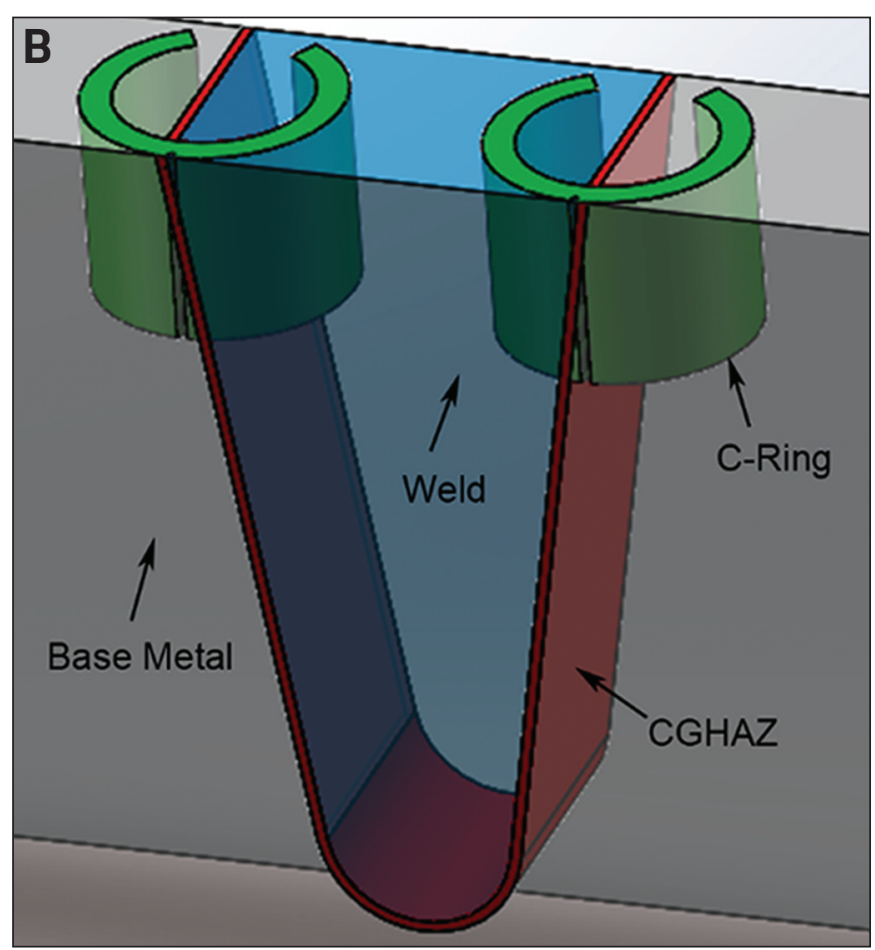

the center of the C-ring. $f$ is the nominal stress, $M P a . D$ is the middle diameter, mm. $t$ is the wall thickness, $\mathrm{mm}$. $E$ is the elastic modulus, $\mathrm{MPa}$. ${ }^{*} Z$ is correction factor. $Z$ is determined by the $Z$ - $(D / t)$ relationship diagram (Fig. 4$)$. The stress applied to the $C$-ring specimen is used to simulate the residual stress during the actual welding process.

The stressed C-ring specimens were placed in a tubular furnace for heat treatment. To prevent oxide formation at the root of the $C$-ring sample, which affects experimental observation, it is critical to adopt a vacuum or nitrogen atmosphere in the furnace. The specimen was maintained at $675^{\circ} \mathrm{C} \pm 3^{\circ} \mathrm{C}$ for $2 \mathrm{~h}$, which is the most sensitive temperature for the reheat cracking of 2.25Cr1Mo0.25V steel welded joint CGHAZ according to our team's previous research results (Refs. 18, 19). The C-ring sample was incubated for $2 \mathrm{~h}$ to simulate the actual postweld heat treatment process. Our team used 2 and $8 \mathrm{~h}$ (the holding time required by the actual manufacturing process) for the comparison experiment. The results of the two experiments was consistent, indicating that the stress applied to the $\mathrm{C}$-ring within $2 \mathrm{~h}$ was completely relaxed, so the holding time was set to $2 \mathrm{~h}$ (Ref. 20). The heating treatment simulation protocol of the specimen is given in Fig. 5 .

After the specimen was cooled down to room tempera-

Table 3 - Welding Parameters

Heat Input $(\mathrm{KJ} / \mathrm{cm})$

Voltage $(V)$

Amperage (A)

Travel Speed $(\mathrm{m} / \mathrm{h})$

Polarity (AC or DC+/-)

Preheating $\left({ }^{\circ} \mathrm{C}\right)$

Interpass Temperature Min./Max. $\left({ }^{\circ} \mathrm{C}\right)$

Backing Weld

Postheating or DHT ( ${ }^{\circ} \mathrm{C}$ and $\left.\mathrm{h}\right)$
30.0

580

34.2

39.9

660

770

870 

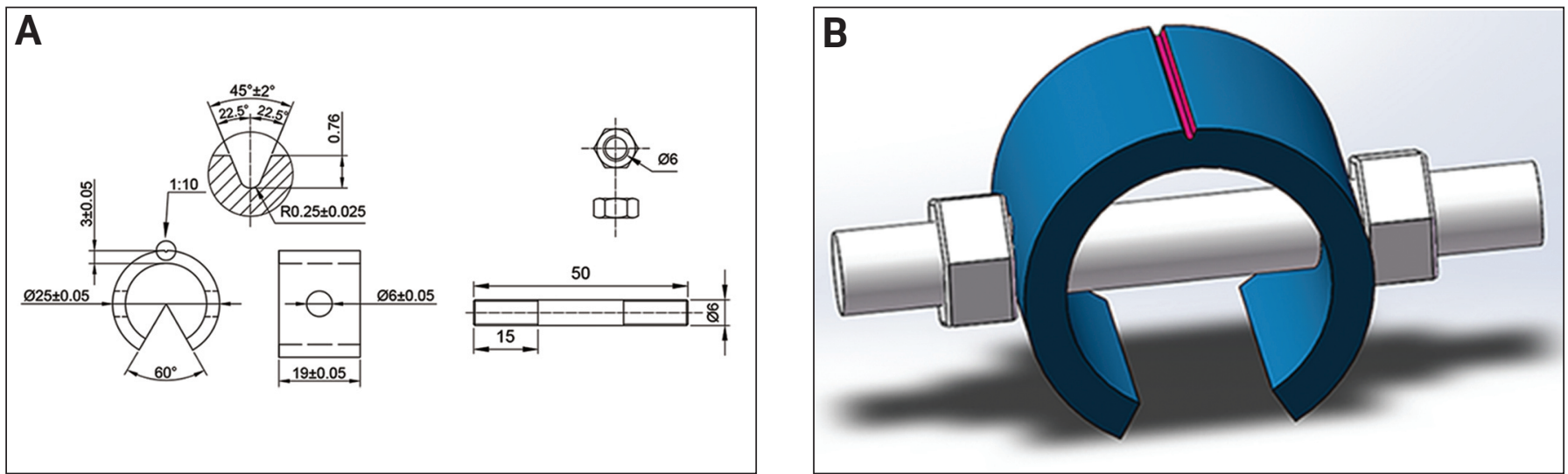

Fig. 3 - Notched C-ring specimen geometry: A - Notched C-ring geometry; B - notched C-ring test specimen.

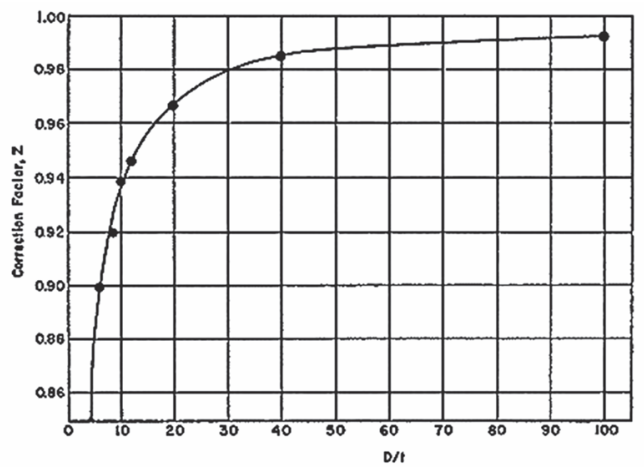

Fig. 4 - The relationship between Z-(D/t).

ture and ultrasonic cleaning was conducted, the crack of the notched C-ring root was examined. Two methods were used for reheat cracking confirmation. One method was a transverse metallography examination in which the $C$-ring was cut transversely. The transverse section was observed under a microscope to observe whether cracks were present at the root of the $\mathrm{C}$-ring notch. Another method was a longitudinal section scanning electron microscopy (SEM) examination in which the notched C-ring was cooled in liquid nitrogen, then fractured longitudinally through the notch. The longitudinal section morphology was studied by SEM inspection.

Under each heat input with a certain loading stress condition, at least six specimens were tested. If the specimens all had reheat cracking on their roots, the test results were marked as "Yes." If none of the specimens had reheat cracking on their roots, the test results were marked as "No." If only some of specimens had reheat cracking on their roots, the test results were marked as "Yes/No." Finally, the test results were statistically analyzed to find the relationship between heat input and the loading stress of the C-ring. The loading stress corresponding to "Yes/No" was the critical stress with the most severe reheat cracking sensitivity.

\section{Results}

The comparison of the two sampling methods above showed that each method had its own advantages to ensure accurate test results. In Method A, the roots of the C-ring

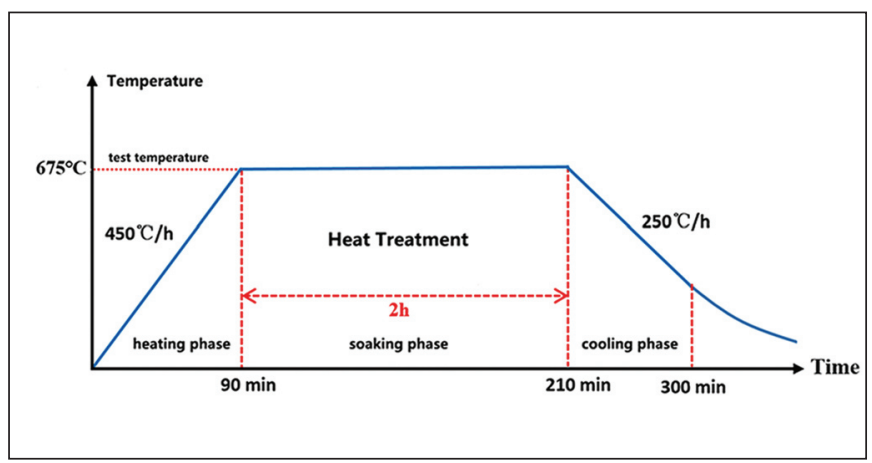

Fig. 5 - Heating treatment protocol.

\begin{tabular}{|c|c|c|c|}
\hline \multirow[t]{2}{*}{ Heat Input } & \multirow[t]{2}{*}{ Method } & \multicolumn{2}{|c|}{$\begin{array}{l}\text { Loading Stress }\left(\times 10^{6} \mathrm{~Pa}\right) \\
\text { ("Y" means crack, "N" means no crack) }\end{array}$} \\
\hline & & 440 & 390 \\
\hline \multirow[t]{2}{*}{$39.9 \mathrm{~kJ} / \mathrm{cm}$} & Method A & $1 / Y 3 / N$ & $4 / N$ \\
\hline & Method B & $3 / Y 3 / N$ & $4 / \mathrm{N}$ \\
\hline
\end{tabular}

could all be located in the CGHAZ (Fig. 6A), but location accuracy could easily be influenced by the machining accuracy and sampling geometry deviation. In Method B, the location accuracy could not be influenced by the machining accuracy and sampling geometry deviation, but only some of the roots of the C-ring notch could be located in the CGHAZ (Fig. 6B). The authors performed the tests at the same condition using the C-ring specimens sampled with the two methods $(39.9 \mathrm{~kJ} / \mathrm{cm})$ (Table 4). The critical stress levels of both specimens were consistent. The difference in materials properties caused by the sampling method has little effect on the generation of cracks.

The C-ring sampling method must ensure its roots can always be at least partly located in the CGHAZ. Method B can meet the sampling requirement and has a lower requirement for the sampling accuracy. All remaining test results are based on Method B.

Before the heat treatment simulation, the notched root of the sample was observed by SEM, and no crack was found (Fig. 7A). After heat treatment simulation, the notched root of the cleaned sample was observed by SEM. It was found 

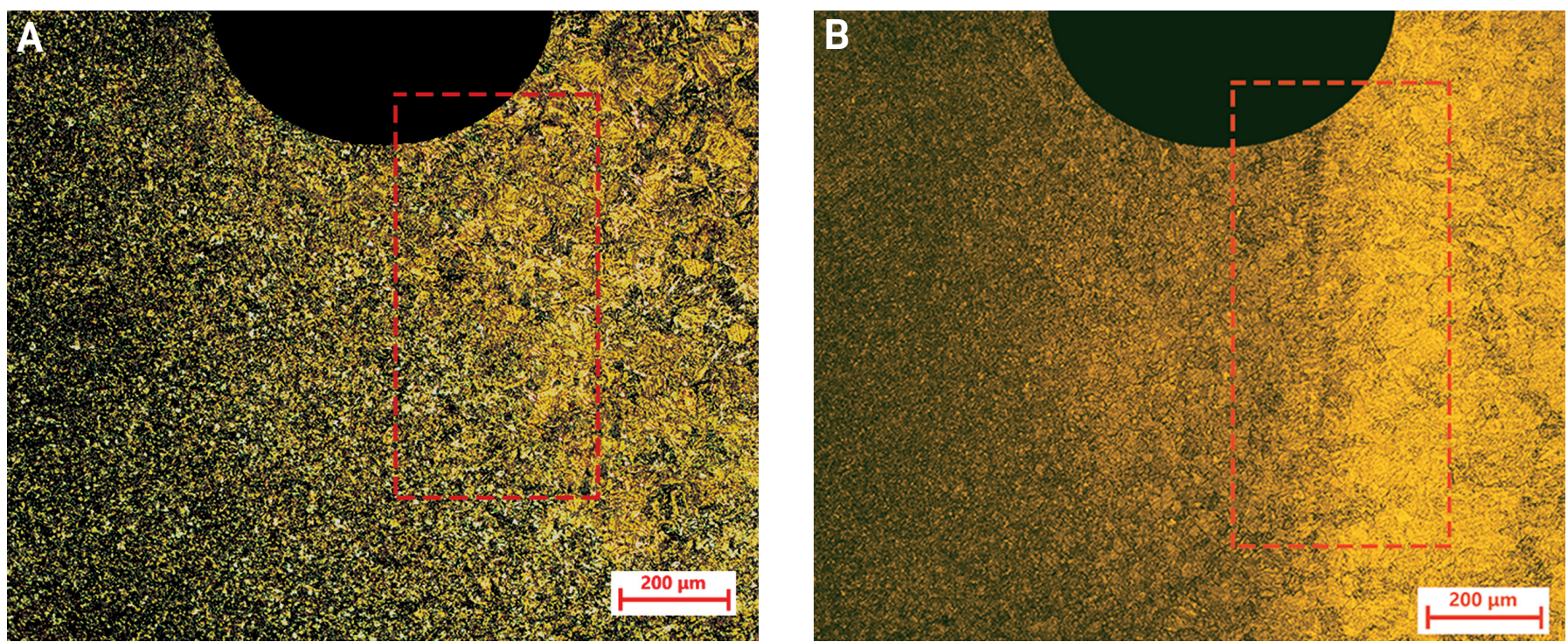

Fig. 6 - Two sampling methods comparison: A - Realistic sectional metallography - Method A; B - realistic sectional metallography Method B.

Table 5 - The Results for the C-Ring Test in Different Heat Input and Loading Stress

Heat Input

$(\mathrm{kJ} / \mathrm{cm})$

\begin{tabular}{cccc} 
& 590 & 565 & 5 \\
\hline 25.9 & $6 \mathrm{Y}$ & $3 \mathrm{Y} / 3 \mathrm{~N}$ & $6 \mathrm{~N}$ \\
30.0 & $6 \mathrm{Y}$ & $/$ & $6 \mathrm{Y}$ \\
34.2 & & & $6 \mathrm{Y}$ \\
39.9 & & & $6 \mathrm{Y}$ \\
45.1 & & &
\end{tabular}

Loading Stress $\left(\times 10^{6} \mathrm{~Pa}\right)$

("Y" means crack, "N" means no crack)

\begin{tabular}{lcccccc}
540 & 515 & 490 & 465 & 440 & 415 & 390 \\
$6 \mathrm{~N}$ & $2 \mathrm{Y} / 4 \mathrm{~N}$ & $6 \mathrm{~N}$ & & & & \\
$6 \mathrm{Y}$ & $/$ & $6 \mathrm{Y}$ & $1 \mathrm{Y} / 5 \mathrm{~N}$ & $6 \mathrm{~N}$ & & \\
$6 \mathrm{Y}$ & $/$ & $6 \mathrm{Y}$ & $/$ & $3 \mathrm{Y} / 3 \mathrm{~N}$ & $/$ & $6 \mathrm{~N}$ \\
$6 \mathrm{Y}$ & & $6 \mathrm{Y}$ & $3 \mathrm{Y}$ & $3 \mathrm{Y} / 3 \mathrm{~N}$ & $6 \mathrm{~N}$ \\
\hline
\end{tabular}

that a continuous and tortuous crack was distributed on the roots (Fig. $7 \mathrm{~B})$.

Two cracked notched C-ring specimens were selected for circumferential cutting, and the section was observed by a metallographic microscope. It was observed from the metallographic diagram that the microstructure around the crack could be roughly divided into three regions: 1) weld, 2) finegrained heat-affected zone (FGHAZ), and 3) CGHAZ (Fig. 8). All cracks occurred in CGHAZ. The remaining cracked notched $\mathrm{C}$-ring samples were broken along the notch. The longitudinal section morphology of the fractured $\mathrm{C}$-ring was observed, revealing that all of the sections showed a part of the black region attached to the entire white region (Fig. 9).

Specimens made from the welded joint under different welding parameters were tested in the notched C-ring test. The results of the notched $\mathrm{C}$-ring test for five given heat input conditions and nine loading stress conditions are summarized in Table 5.

\section{Discussion}

\section{Reheat Cracking Confirmation}

During testing, it was necessary to judge whether the crack at the root of the notched C-ring was reheat cracking.
From Fig. 9, it was inferred that the crack occurred during heat treatment simulation.

All cracks occurred in the CGHAZ. The root of the notch was located in the CGHAZ, and the stress concentration at the root of the notch caused the stress level to rise, causing cracks in the C-ring notched root. Under the action of stress concentration, the crack propagated along the CGHAZ structure in the high-stress state. When the crack reached the CGHAZ structure in the low-stress state, the crack finally stopped (Fig. 10A). An important factor influencing the occurrence of this crack is that stress occurs on the sensitive microstructure. The more stress the sensitive tissue is subjected to, the easier it is to crack, which is consistent with the characteristics of reheat cracking.

The cracks were classified into two types. One type of crack is a wedge crack, where the intergranular brittle fracture surface is smooth. Generally, under higher stress conditions, this type of crack is easy to produce (Fig. 10B). Another type of crack is a void aggregate crack. Here, the cavity nucleates on the grain boundary and then grows and intersects. Eventually, the creep plasticity of the grain boundary reduces, and cracking occurs. Generally, under lower stress conditions, this type of crack is easy to produce (Fig. 10C). Whether it is a wedge crack or a void aggregation crack, they are typically cracked along the prior austenite grain boundary, which is consistent 

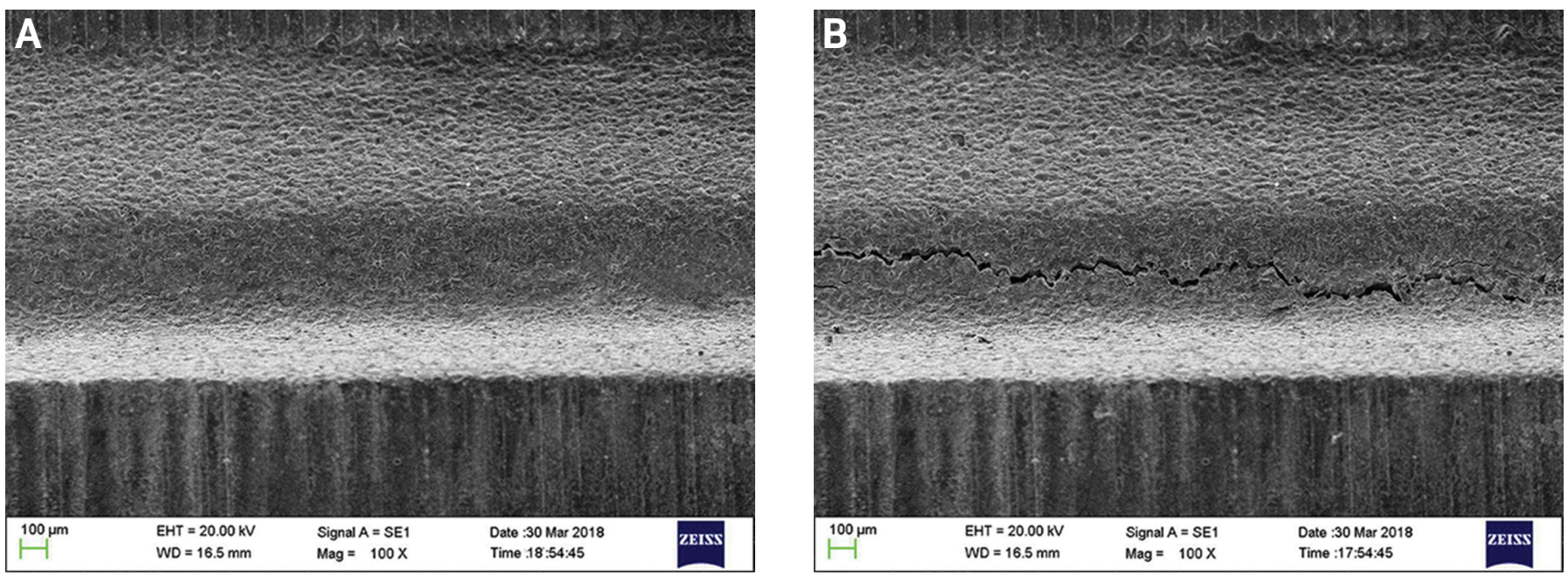

Fig. 7-A $-C$-ring notched root before heat treatment $\left(30.0 \mathrm{~kJ} / \mathrm{cm}, 565 \times 10^{6} \mathrm{~Pa}\right) ; \mathrm{B}-C$-ring notched root after heat treatment $\left(30.0 \mathrm{~kJ} / \mathrm{cm}, 565 \times 10^{6} \mathrm{~Pa}\right)$.

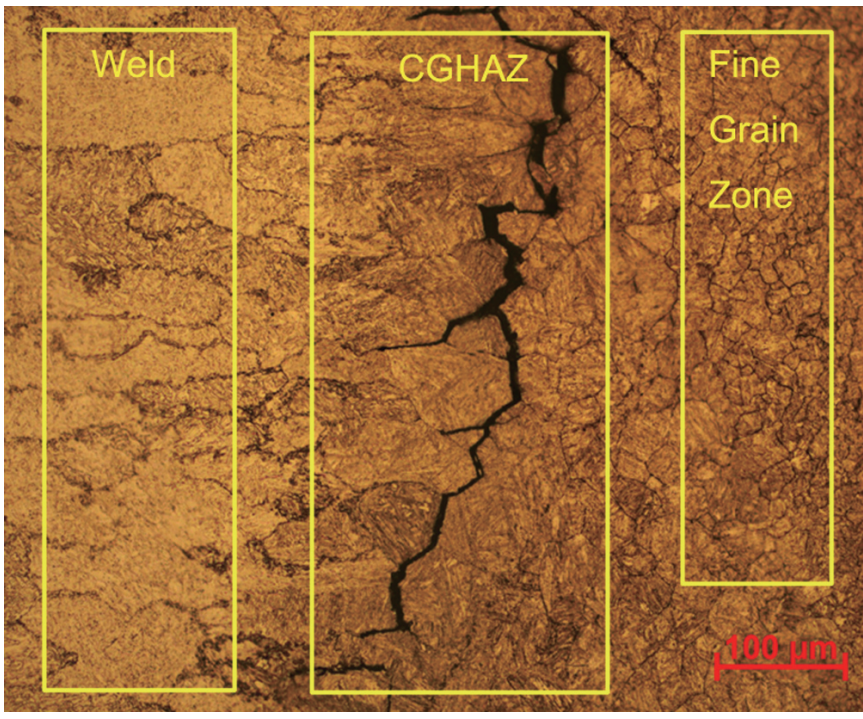

Fig. $8-$ Reheat cracking in the root of the $C$-ring notch $(25.9 \mathrm{~kJ} / \mathrm{cm}, 590 \times 106 \mathrm{~Pa})$.

with the characteristics of reheat cracking. The crack originates from the CGHAZ and then stops in the microstructure of the weld and FGHAZ (Fig. 10B), indicating that in the welded joint structure, the susceptibility to reheat cracking in CGHAZ is actually the highest.

Scanning electron microscopy revealed that the black region of the fracture surface of the $\mathrm{C}$-ring (Figs. 9 and 11A) showed a typical intergranular fracture morphology, which was consistent with the reheat cracking characteristics (Fig. 11B). The notch root of the C-ring samples was only partially located in the CGHAZ. Therefore, it was determined that the black region on the section was the CGHAZ structure and that reheat cracking occurred in the CGHAZ. The fracture surface morphology in the remaining white region was a typical transgranular fracture (Fig. 11C).

It can be concluded in the notched $C$-ring test, the crack that occurred during heat treatment is reheat cracking, and the position where the reheat cracking occurred is a CGHAZ structure.

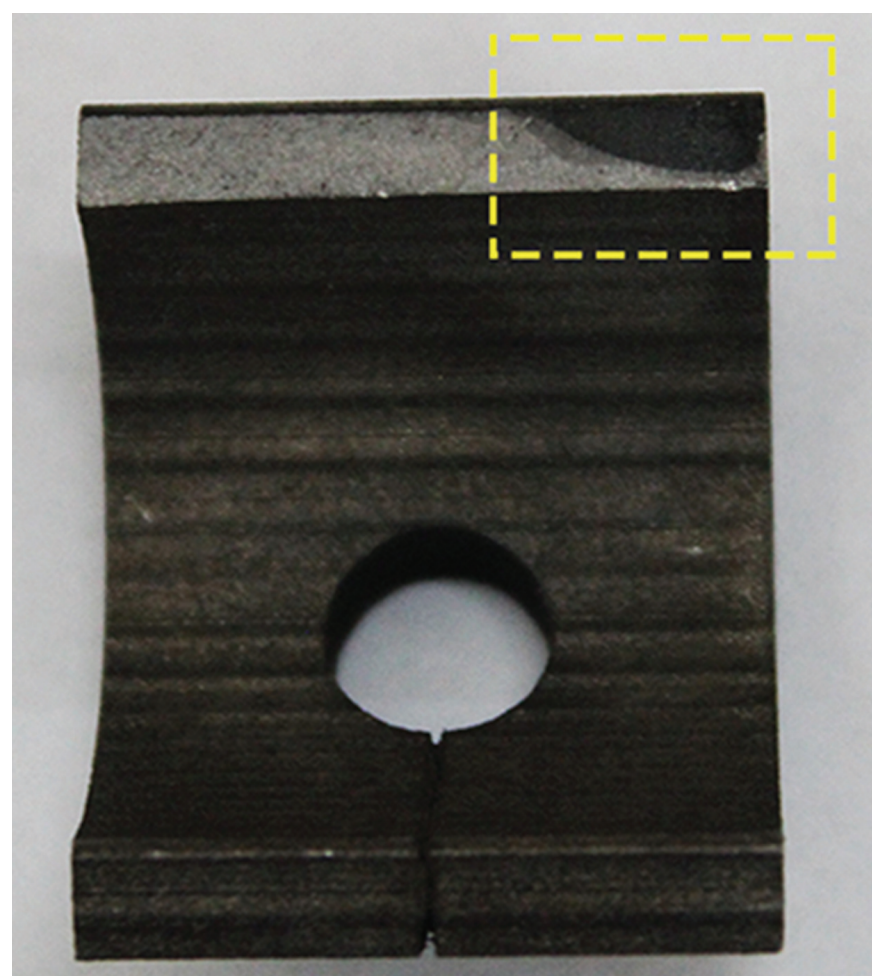

Fig. 9 - Notched C-ring specimen after brittle fracture.

\section{Relationship between Heat Input, Critical Stress, and Reduction of Area}

The relationship between the heat input and critical stress is summarized in Table 6. It was found that as the heat input increases, the material becomes more sensitive to reheat cracking, and the critical stress of the $C$-ring gradually decreases. Therefore, the critical stress of the C-ring could be used as an evaluation index for reheat cracking sensitivity. To establish specific evaluation criteria, four different reheat cracking sensitivities - not susceptible, slightly susceptible, highly susceptible, and extremely susceptible must be clearly distinguished. In the Gleeble ${ }^{\circledR}$ simulation 

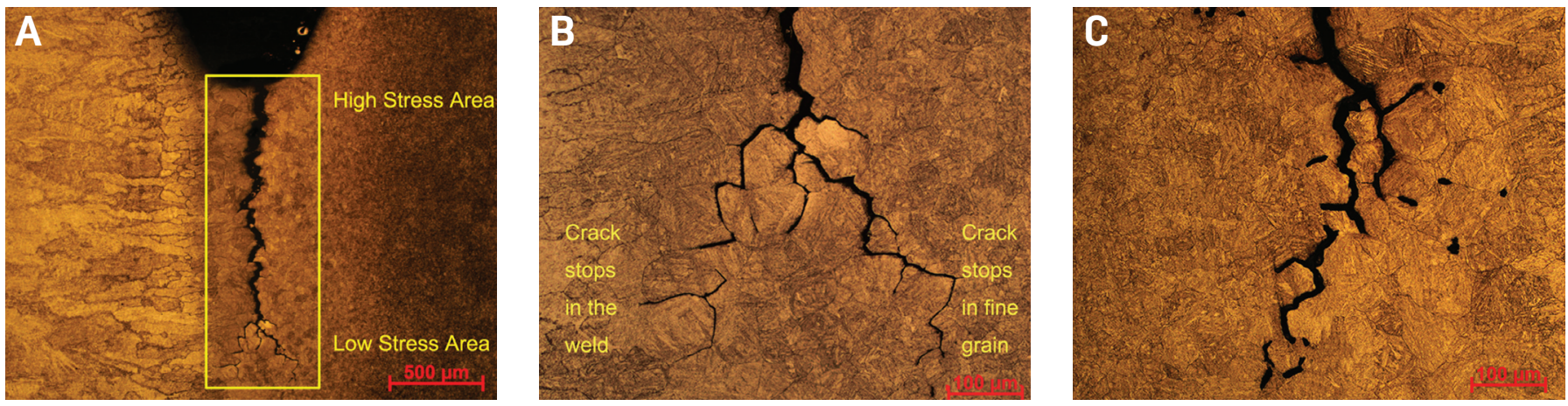

Fig. 10 - Crack in the root of the C-ring notch $\left(34.2 \mathrm{~kJ} / \mathrm{cm}, 590 \times 10^{6} \mathrm{~Pa}\right)$ : A - Overview; B - wedge crack; C - void aggregation crack.
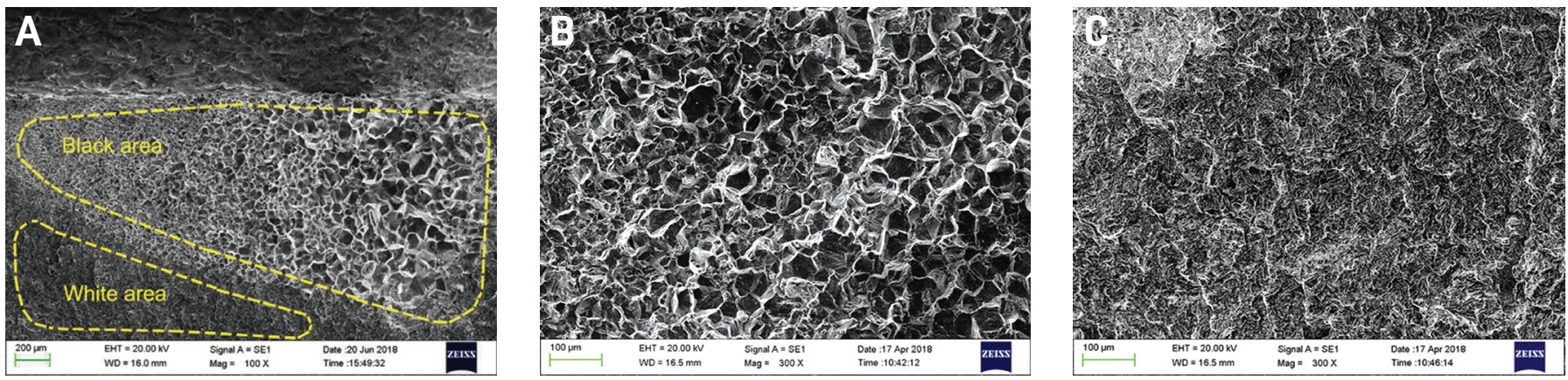

Fig. 11 - Fractured surface of cracked C-ring $\left(30.0 \mathrm{~kJ} / \mathrm{cm}, 565 \times 10^{6} \mathrm{~Pa}\right)$ : A - Fracture morphology under electron microscopy $(\times 100)$; $B$ - black area intergranular crack; $C$ - white area transgranular crack.

Table 6 - Heat Input and Critical Stress Relationship

Heat Input (kJ/cm)

Critical Stress $\left(\times 10^{6} \mathrm{~Pa}\right)$

$\begin{array}{cc}25.9 & 565 \\ 30.0 & 515 \\ 34.2 & 465 \\ 39.9 & 440 \\ 45.1 & 415\end{array}$

test, the four discrimination criteria of reheat cracking sensitivity were as follows: RoA > 20\% — not susceptible; $10 \%$ $<$ RoA $<20 \%$ - slightly susceptible; $5 \%<$ RoA $<10 \%-$ highly susceptible; and RoA $<5 \%$ - extremely susceptible.

To make the notched C-ring test clearly distinguish the four reheat cracking sensitivity categories, the Gleeble ${ }^{\circledR}$ simulation test was introduced, which could serve as a reference for the establishment of specific evaluation criteria. The authors had previously done a Gleeble ${ }^{\circledR}$ simulation test to verify the reheat cracking sensitivity of the $2.25 \mathrm{Cr} 1 \mathrm{Mo} 0.25 \mathrm{~V}$ simulated CGHAZ (Refs. 19-21). For the five welding heat input parameters used in the notched C-ring test, the Gleeble ${ }^{\circledR}$ simulation test under the five given heat input conditions was performed to simulate the corresponding CGHAZ by changing the welding heat input and the peak temperature residence time. The peak temperature residence time was varied while maintaining the peak temperature and heating rate to simulate the microstructures under different weld heat input. Then, the tensile test was carried out at the reheat cracking sensitive temperature $\left(675^{\circ} \mathrm{C}\right)$. Finally, the relationship between the welding heat input and the RoA was obtained (Table 7). With an increase in heat input, the RoA is gradually reduced, and the sensitivity to reheat cracking is higher. Then, the relationship between heat input, critical stress, and RoA can be obtained (Fig. 12). As the RoA increases, the reheat cracking sensitivity gradually decreases, while the critical stress of the C-ring increases gradually.

\section{CGHAZ Notched C-Ring Test Criteria}

According to the curve and evaluation criteria from the Gleeble ${ }^{\circledR}$ simulation test (Refs. 10-13), when the RoA was $20 \%$, the corresponding nominal loading stress of the C-ring was $500 \times 10^{6} \mathrm{~Pa}$, which could be used to distinguish between "not susceptible" and "slightly susceptible" in the notched Cring reheat cracking test. When the RoA was $10 \%$, the corresponding nominal stress was $415 \times 10^{6} \mathrm{~Pa}$, which could be used to distinguish between "slightly susceptible" and "highly susceptible." When the RoA was 5\%, the corresponding nominal stress was $375 \times 10^{6} \mathrm{~Pa}$, which could be used to distinguish between "highly susceptible" and "extremely susceptible."

The specific evaluation criteria (Table 8) of the notched Cring reheat cracking sensitivity test was established as the following: nominal stress $>500 \times 10^{6} \mathrm{~Pa}$ - not susceptible; 415 $\times 10^{6} \mathrm{~Pa}<$ nominal stress $<500 \times 10^{6} \mathrm{~Pa}-$ slightly susceptible; $375 \times 10^{6} \mathrm{~Pa}<$ nominal stress $<415 \times 10^{6} \mathrm{~Pa}$ - highly susceptible; and nominal stress $<375 \times 10^{6} \mathrm{~Pa}$ - extremely susceptible. This evaluation method can be used to evaluate the sensitivity of reheat cracking in the CGHAZ of $2.25 \mathrm{Cr} 1 \mathrm{Mo} 0.25 \mathrm{~V}$ steel weld joints in an engineering project. C-ring samples are made directly from actual engineering welded joints. 


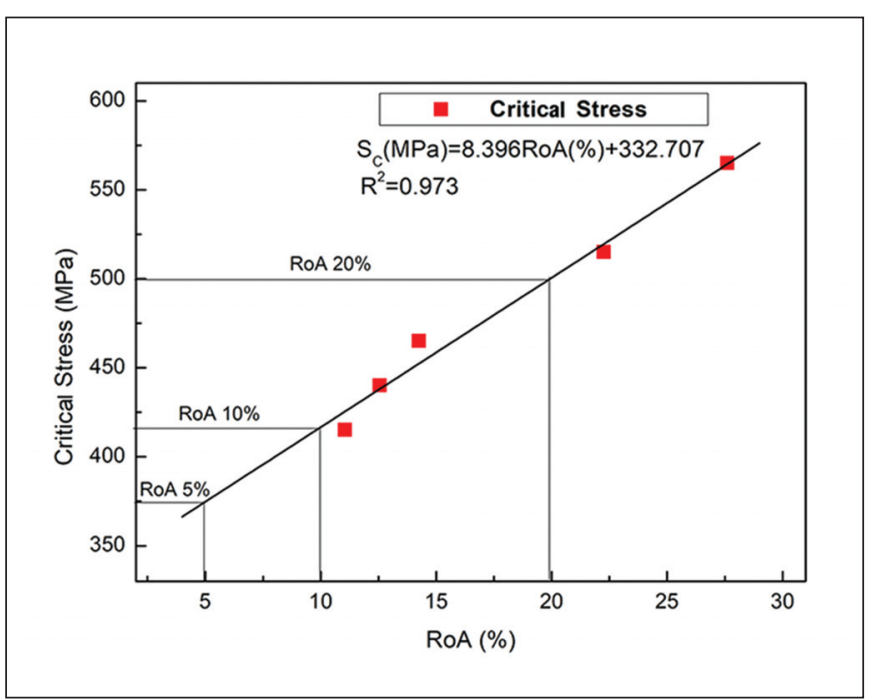

Fig. 12 - Relationship between the critical stress and RoA.

When the CGHAZ notched C-ring test is used to evaluate reheat cracking sensitivity of $2.25 \mathrm{Cr} 1 \mathrm{Mo} 0.25 \mathrm{~V}$ steel CG$\mathrm{HAZ}$, the detailed operation steps are as follows:

1) A load of $500 \times 10^{6} \mathrm{~Pa}$ is used as the initial loading stress of the notched C-ring sample, and the amount of change in the outer diameter of the C-ring is $0.510 \mathrm{~mm}$. After $675^{\circ} \mathrm{C} \times 2 \mathrm{~h}$ of heat treatment, check the notch root of the $\mathrm{C}$-ring specimen for reheat cracking. If not, it indicates that the nominal stress is greater than $500 \times 10^{6} \mathrm{~Pa}$, which is classified as "not susceptible." If yes, the nominal stress is less than $500 \times 10^{6} \mathrm{~Pa}$, and test step 2 is performed.

2) Load the $\mathrm{C}$-ring to $415 \times 10^{6} \mathrm{~Pa}$, and the $\mathrm{C}$-ring outer diameter change amount is $0.420 \mathrm{~mm}$. After heat treatment, if the $C$-ring sample does not produce reheat cracking, the nominal stress is greater than $415 \times 10^{6} \mathrm{~Pa}$, and the reheat cracking is directly classified as "slightly susceptible." If yes, the nominal stress is less than $415 \times 10^{6} \mathrm{~Pa}$, and test step 3 is performed.

3) Load the C-ring specimen to $375 \times 10^{6} \mathrm{~Pa}$, the $\mathrm{C}$-ring outer diameter change amount is $0.390 \mathrm{~mm}$. After heat treatment, if the $C$-ring sample does not produce reheat cracking, the nominal stress is greater than $375 \times 10^{6} \mathrm{~Pa}$, and the reheat cracking is directly classified as "highly susceptible." If yes, the nominal stress is less than $375 \times 10^{6} \mathrm{~Pa}$, and the reheat cracking is classified as "extremely susceptible."

\section{Conclusion}

The evaluation method of CGHAZ reheat crack sensitivity using notched $\mathrm{C}$-ring is studied in this paper. The sampling method of the $C$-ring was determined by comparison of two sampling methods. The typical characteristics of the wedge crack and void aggregate crack were observed, and the reheat cracking occurring at the notch root of the $C$-ring was validated. The notched $\mathrm{C}$-ring tests were carried out with specimens taken from welded joints manufactured at five welding heat inputs. The results showed that as the heat input increased, the reheat cracking sensitivity gradually increased. Based on the evaluation standard of the Gleeble ${ }^{\circledR}$ simulation test, the relationship between the welding heat

\begin{tabular}{|c|c|c|}
\hline \multicolumn{3}{|c|}{ Table 7 - Heat Input and RoA Relationship } \\
\hline Heat Input $(\mathrm{kJ} / \mathrm{cm})$ & & RoA (\%) \\
\hline 25.9 & & 27.61 \\
\hline 30.0 & & 22.26 \\
\hline 34.2 & & 14.25 \\
\hline 39.9 & & 12.45 \\
\hline 45.1 & & 11.05 \\
\hline \multicolumn{3}{|c|}{ Table 8 - Criteria to Evaluate Reheat Cracking Susceptibility } \\
\hline $\begin{array}{l}\text { Reheat Cracking } \\
\text { Sensitivity }\end{array}$ & RoA & Nominal Stress \\
\hline Not Susceptible & $>20 \%$ & $>500 \times 10^{6} \mathrm{~Pa}$ \\
\hline Slightly Susceptible & $10 \sim 20 \%$ & $415 \times 10^{6} \mathrm{~Pa} \sim 500 \times 10^{6} \mathrm{~Pa}$ \\
\hline Highly Susceptible & $5 \sim 10 \%$ & $375 \times 10^{6} \mathrm{~Pa} \sim 415 \times 10^{6} \mathrm{~Pa}$ \\
\hline Extremely Susceptible & $<5 \%$ & $<375 \times 10^{6} \mathrm{~Pa}$ \\
\hline
\end{tabular}

input, critical stress, and RoA was established. Subsequently, notched C-ring test evaluation criteria were established to evaluate the reheat cracking sensitivity: nominal stress $>$ $500 \times 10^{6} \mathrm{~Pa}-$ not susceptible; $415 \times 10^{6} \mathrm{~Pa}<$ nominal stress $<500 \times 10^{6} \mathrm{~Pa}$ - slightly susceptible; $375 \times 10^{6} \mathrm{~Pa}<$ nominal stress $<415 \times 10^{6} \mathrm{~Pa}-$ highly susceptible; and nominal stress $<375 \times 10^{6} \mathrm{~Pa}$ - extremely susceptible. A large number of tests are recommended to verify and correct the preliminary evaluation method and criterion proposed in this study. A standard evaluating reheat cracking with the facile notched $C$-ring method will be established through the accumulation of a large amount of data.

\section{Acknowledgments}

The authors thank all contributors of this work and all the people met during this work period. This research was financially supported by the National Basic Research Program of China (973 Program, No. 2015CB057602).

\section{References}

1. Tamaki, K., Suzuki, J., and Li, M. L. 1993. Influence of vanadium carbide on reheat cracking of Cr-Mo steels: Study of reheat cracking of Cr-Mo steels. Transactions of the Japan Welding Society 24(2): 87-93.

2. Prager, M. 2009. A program to update materials and process standards for fabrication of heavy wall vessels of 2.25CrlMo0.25V alloy for service with hydrogen at high pressures and temperatures. New York: MPC.

3. Chauvy, C., and Pillot, S. 2009. Prevention of weld metal reheat cracking during $\mathrm{Cr}-\mathrm{Mo}-\mathrm{V}$ heavy reactors fabrication. Pressure Vessels and Piping Conference July 26-30, Prague, Czech Republic.

4. American Petroleum Institute. 2011. Fabrication con- 
siderations for vanadium-modified $\mathrm{Cr}$-Mo steel heavy wall pressure vessels. API Technical Report 934-B.

5. Zhu, Z. Q., Zhang, J. J., and Zou, P. J. 2013. Reheat crack analysis of T23 / 12CrlMoV weld. Boiler Technology 44(1): 53-56.

6. Ren, X., and Wang, C. B. 2012. Research progress on reheat cracking of low alloy steel welded joints for pressure vessels. Materials for Mechanical Engineering 36(5): 5-9.

7. Long, H. G., Long, Y., and Chen, H. D., 2011. Mechanism of T23/12Cr1MoV dissimilar steel welding failure in high temperature reheater. Electric Power 44: 70-73.

8. Ren, Y. B., Wang, W., and Ping, S. B. 2016. Failure analysis of T23/TP347H dissimilar steel welded tube joint for high temperature reheater. Heat Treatment of Metals 41: 199-203.

9. Pillot, S., and Chauvy, C. 2012. Standard procedure to test 2.25Cr1Mo0.25Vsaw filler material reheat cracking susceptibility. American Society of Mechanical Engineers 6: 813-24.

10. American Petroleum Institute. 2010. Guidance for inspection for transverse reheat cracking. API Recommended Practice 934-A.

11. Vinckier, A., and Dhooge, A. 1976. Susceptibility to Reheat Cracking of Nuclear Pressure Vessel Steels. International Institute of Welding.

12. Lundin, C. D., Menon, R. K., and Chen, Z. 1989. Post weld heat treatment crack in high strength low alloy steels. Welding Research Council Bulletin 349: 22-30.

13. Lundin, C. D., Henning, J. A., and Menon, R. 1989. Post weld heat treatment crack in chromium-molybdenum steels. Welding Research Council Bulletin 349: 1-21.

14. Maxwell, C. T. 2012. Development and use of a simple test method to evaluate reheat cracking sensitivity in the weld deposit region of a submerged arc welding. M.S. thesis. Knoxville, Tenn.; University of Tennessee.

15. International Organization for Standardization.
2011. Steel plates for boilers and pressure vessels. Steel flat products for pressure purposes-technical delivery conditions - Part 2: Non-alloy and alloy steels with specified elevated temperature properties, NEQ. ISO 9328-2.

16. Lundin, C. D., and Khan, K. K. 1996. Fundamental studies of the metallurgical causes and mitigation of reheat cracking in $1 \frac{1}{4} \mathrm{Cr}-1 / 2 \mathrm{Mo}$ and $2 \frac{1}{4} \mathrm{Cr}$ - $1 \mathrm{Mo}$ steels. Welding Research Council Bulletin 409: 1-117.

17. American Society for Testing Materials. 2013. Standard Practice for Making and Using C-Ring Stressing-Corrosion Test Specimen.

18. Huang, Y., Xu, C., Chen, J., et al. 2017. Evaluation method study on the susceptibility of reheat cracking in CGHAZ of Chinese 2.25Cr1Mo0.25V Steel. Proceeding of $9^{\text {th }}$ National Symposium on Pressure Vessel, Nov. 20-22, Hefei, Anhui.

19. Han, Y., Chen, X., Fan, Z., et al. 2014. Reheat cracking sensitivity of CGHAZ in vanadium modified $2.25 \mathrm{Cr} 1 \mathrm{Mo}$ welds. Proceedings of the ASME 2014 Pressure Vessels and Piping Division Conference, July 20-24; Anaheim, Calif.

20. Xu, C. 2016. Study on the susceptibility of reheat cracking in 2.25Cr1Mo0.25V Steel. M.S. thesis. Shanghai: East China University of Science and Technology.

21. Huang, Y., Xu, C., Chen, J., et al. 2018. The notched C-ring test to evaluate reheat cracking susceptibility of CG$\mathrm{HAZ}$ in $2 \frac{1}{4} \mathrm{Cr}-1 \mathrm{Mo}-1 / 4 \mathrm{~V}$ steel welded joints. Proceedings of the ASME 2018 Pressure Vessels and Piping Division Conference, July 15-19, Prague, Czech Republic.

LI ZHANG (Izhang@ecust.edu.cn), KAI WANG, YU HUANG, CHIXU, and IN CHEN are with the School of Mechanical and Power Engineering, East China University of Science and Technology, Shanghai, China.

\section{Welding Journal Now Publishing Direct Object Identifier (DOI) Numbers}

Dear members of the welding research community,

Note that in each issue of the Welding Journal Research Supplement, we are including Direct Object Identifier (DOI) numbers with each of the papers published in print and online. A direct object identifier is a unique alphanumeric string assigned by a registration agency (we are using Crossref.org) to identify content and provide a persistent link to its location on the Internet. Our decision to begin assigning a DOl for each paper comes directly from a request by the research community.

As part of our obligation to Crossref.org, we are asked to provide DOI numbers, when available, in the references section of papers. So, if you have submitted a paper to the Welding Journal or are planning on submitting a paper, we ask that you update your references to include DOI numbers whenever possible.

Thank you.

Annette Alonso

Publisher, Welding Journal 